\title{
PERCURSO TRADUTÓRIO EM TEXTOS HISTÓRICOS SOBRE A VIAGEM DE DESCOBRIMENTO DO RIO AMAZONAS
}

\author{
Andréa Cesco 1 \\ 1-Universidade Federal de Santa Catarina, Florianópolis, Santa Catarina, Brasil/ \\ $\mathrm{CNPq}$ \\ Mara Gonzalez Bezerra² \\ 2UNIASSELVI, Indaial, Santa Catarina, Brasil
}

\section{Introdução}

Os dois capítulos traduzidos por nós - do espanhol ao português - fazem parte de uma extensa introdução (com duzentas e trinta e nove páginas) escrita pelo renomado historiador chileno José Toribio Medina (1852-1930), responsável pela edição da obra Descubrimiento del Río de las Amazonas, ${ }^{1}$ publicada em 1894, em Sevilha, Espanha. A obra, que traz na íntegra a Relación, de autoria do cronista espanhol frei Gaspar de Carvajal (1504-1584), considerada uma das principais referências no estudo da conquista das Américas, oferece um conjunto de relatos documentados sobre a expedição ao rio Amazonas realizada pelo expedicionário espanhol

\footnotetext{
1 A obra, disponibilizada em formato pdf, está armazenada na Biblioteca Digital do Senado Federal. https://www2.senado.leg.br/bdsf/item/id/518714. Acesso em outubro de 2020. "Carvajal, Gaspar de, 1504-1584. Outros autores: Medina, José Toríbio, 1852-1930. Publicador: Sevilla: Imprenta de E. Rasco. Data de publicação: 1894. Descrição física: ccxxxviii, 278, [1] p.: il., grav.; 24 cm. Responsabilidade: Com introdução histórica e algumas ilustrações de José Toribio Medina”.
} 
Capitão Francisco de Orellana (1511-1546) e por sua tropa.

Salientamos que a obra já foi traduzida e anotada ao português por C. de Melo-Leitão - Descobrimentos do Rio das Amazonas -, em 1941, publicada pela Companhia Editora Nacional. ${ }^{2}$ No entanto, apesar do editor/tradutor (não há como afirmar quem de fato escreveu), incluir um prefácio de seis páginas e mencionar ou citar alguns trechos da introdução de José Toribio Medina, ele opta por excluí-la. Assim, temos na obra (com 298 páginas) ${ }^{3}$ o seguinte índice: Prefácio (5), Relação que escreveu Frei Gaspar de Carvajal (11), Descobrimento do Rio de Orellana (13), Descobrimento do Rio das Amazonas e suas dilatadas províncias [sic] (81) e, por fim, Novo descobrimento do Grande Rio das Amazonas (125).

Em função dessa exclusão, decidimos selecionar e traduzir dois capítulos (VIII - A Viagem do Descobrimento e XI - Sobre os nomes do Rio), de um total de onze, da introdução histórica escrita, de forma crítica, por José Toribio Medina. Esta seleção se deu por estes serem capítulos que relatam, o cotidiano dos expedicionários, das descobertas, das dificuldades sofridas e das diversas aventuras vivenciadas ao longo do curso do rio Amazonas, inclusive, confrontando e esclarecendo informações. Elas são importantes porque ratificam a participação dos espanhóis na história portuguesa e brasileira e, também, revelam algumas das atrocidades cometidas pelos expedicionários, não sem receberem, muitas vezes, as represálias dos indígenas. As descobertas durante a navegação ao longo do rio Amazonas, a polêmica instaurada sobre os nomes do rio e o debate sobre os diversos nomes pelos quais o rio Amazonas foi chamado em muitas ocasiões são detalhados por Toribio Medina.

Os demais capítulos tratam mais diretamente de Orellana ou Gaspar de Carvajal, conforme a relação a seguir: I. Documentação

${ }^{2}$ Gaspar de Carvajal, Alonso de Rojas e Cristóbal de Acuña. Descobrimentos do Rio das Amazonas. Série 2a, Vol. 203, Brasiliana - Biblioteca Pedagógica Brasileira. Traduzido e anotado por C. de Melo-Leitão. São Paulo, Rio de Janeiro, Recife, Porto Alegre. Companhia Editora Nacional, 1941.

${ }^{3}$ Repositório da Universidade Federal do Rio de Janeiro. http://bdor.sibi.ufrj.br/ handle/doc/287. Acesso em 03 de novembro de 2020.

Cad. Trad., Florianópolis, v. 41, n $^{0}$ esp. 1, p. 213-230, jan/jul, 2021. 
da viagem de Orellana; II. Fr. Gaspar de Carvajal, cronista da expedição de Orellana; III. Autores que escreveram sobre a viagem de Orellana; IV. Orellana no teatro; V. Dados biográficos de Francisco de Orellana; VI. Francisco de Orellana na expedição de Gonzalo Pizarro; VII. A traição de Orellana; IX. Os companheiros de Orellana; X. Expedição de Orellana à Nueva Andalucía.

A partir desse breve comentário introdutório, a explanação a seguir está dividida em três momentos: o primeiro, que trata do cronista da expedição, Gaspar de Carvajal, e da obra Descubrimiento del Río de las Amazonas, a partir da sua Relación; o segundo, que apresenta o historiador José Toribio Medina, editor e autor da introdução histórica da obra; e o último, que discorre sobre o processo tradutório.

\section{Descubrimiento del Río de las Amazonas: Gaspar de Carvajal}

Gaspar de Carvajal nasceu em Trujillo, Espanha, em 1504, e faleceu no Peru, em 1584. Recebeu suas ordens eclesiásticas Dominicanas em setembro de 1535 . Um ano depois de ser ordenado como frei, alistou-se para evangelizar os novos súditos no território do Peru. Sua posição e compromisso como evangelizador da Santa Fé Católica ajudou-o a se estabelecer como um grande personagem da conquista Espanhola. Três anos após sua partida da Espanha, constituiu o primeiro Mosteiro dominicano em Lima. Foi nomeado Vigário Provincial. Este nível de prestígio em territórios americanos lhe abriu oportunidades para participar em futuras expedições, como guia espiritual dos expedicionários espanhóis.

Em 1540, Carvajal se une à expedição de Gonzalo Pizarro, conquistador espanhol e governador de Quito (Equador), como capelão, que buscava o país da canela, ao leste de Quito e da Amazônia. A expedição, em condições difíceis, atravessou os Andes e entrou na selva amazônica, um território inóspito. Mas, Pizarro, decepcionado por encontrar poucas árvores de canela, 
e preocupado por seus homens estarem adoecendo e sofrendo com a fome, decide voltar. Assim, a expedição com Francisco de Orellana Bejarano Pizarro y Torres de Altamirano (1511-1546), segundo no comando da embarcação de Pizarro, começa quando este, em 1541, decide continuar a exploração do rio por sua conta, tendo Carvajal como cronista para realizar os registros. Após o término da viagem, quando encontra o Oceano, Orellana retorna à Espanha. Mas, sem demora, em 1544, decide retornar ao Amazonas em uma nova expedição.

Orellana morreu em 1546, na região norte do Brasil, acometido de febres, sem ter dado cabo da nova expedição. A sua importância reside no fato de ter realizado uma navegação bem sucedida e de ter compilado dados para uma cartografia do rio Amazonas, já que foi a primeira expedição a realizar um mapa da região do rio Amazonas. Toribio Medina, no primeiro parágrafo do capítulo VIII do Descubrimiento, enaltece o capitão espanhol:

\begin{abstract}
[...] desde que parte das aldeias de Aparia, sua perseverança nos trabalhos, suas características de chefe prudente e precavido, sua firmeza e energia, sua coragem a toda prova naquela perigosa e audaciosa viagem de descobrimento, tornam-lhe digno de indiscutível glória e por ninguém jamais disputada até agora. ${ }^{4}$ (Carvajal, 140)
\end{abstract}

Os relatos publicados em Descubrimiento del Río de las Amazonas, que resultaram em dezenove capítulos, foram escritos, no período de dezembro de 1541 até 11 de setembro de 1542, pelo cronista - um dos sobreviventes da expedição - Gaspar de Carvajal. Aqui é importante fazer um aparte para mencionar que Car-

${ }^{4}$ [...] desde que parte del pueblo de Aparia su constancia en los trabajos, sus condiciones de jefe prudente y precavido, su firmeza y energía, su coraje á toda prueba en aquel peligroso y atrevido viaje de descubrimiento, le hacen digno de gloria indiscutible y por nadie hasta ahora disputada.

Cad. Trad., Florianópolis, v. 41, $\mathrm{n}^{0}$ esp. 1, p. 213-230, jan/jul, 2021.216 
vajal narra os acontecimentos da expedição em sua Relación del nuevo descubrimiento del famoso río Grande que descubrió por muy gran ventura el capitán Francisco de Orellana, que por mais de 300 anos permanece inédita, até que em 1855 a Real Academia de Historia de Madrid publica algumas partes desses escritos na Historia general y natural de las Indias, de Gonzalo Fernández de Oviedo. Infelizmente a transcrição sofreu inúmeros erros, a ponto de ter sido considerada por alguns bibliófilos como apócrifa, alterada e deficiente. No entanto, só em 1894 a Relación de Carvajal é publicada, integralmente, em Descubrimiento del Río de las Amazonas, pelo historiador chileno José Toribio Medina, e amplamente revisada por H.C. Heaton em 1934. Estas são as informações que constam na terceira capa da edição de 1894:

\begin{abstract}
Descubrimiento del Río de Las Amazonas, segundo a $R e$ lación, até agora inédita, de Fr. Gaspar de Carvajal com outros documentos referentes a Francisco de Orellana e seus companheiros, publicados à custa do Excelentíssimo Sr. Duque De T'serclaes de Tilly, com uma introdução histórica e algumas ilustrações por José Toribio Medina da Academia Chilena, Correspondente das Reales Academias de la Lengua y de la Historia, de Buenas Letras de Sevilha e do Instituto Geográfico Argentino. Sevilha: Imprensa de E. Rasco, Bustos Tavera, núm. I. 1894. ${ }^{5}$
\end{abstract}

Nos relatos o cronista conta o cotidiano da expedição, onde foram maiores as dificuldades encontradas no percurso do que as

5 Descubrimiento del Río de Las Amazonas, según la Relación hasta ahora inédita de Fr. Gaspar de Carvajal con otros documentos referentes á Francisco de Orellana y sus compañeros, publicados á expensas del Excmo. Sr. Duque De T'serclaes de Tilly, con una introducción histórica y algunas ilustraciones por José Toribio Medina de la Academia Chilena, Correspondiente de las Reales Academias de la Lengua y de la Historia, de la de Buenas Letras de Sevilla y del Instituto Geográfico Argentino. Sevilla: Imprenta de E. Rasco, Bustos Tavera, núm. I. 1894.

Cad. Trad., Florianópolis, v. 41, no esp. 1, p. 213-230, jan/jul, 2021. 
glórias das descobertas. As baixas humanas, os feridos, as frustrações, as relações nem sempre amigáveis com os indígenas, os mosquitos, as doenças e, muito provavelmente, o calor a que não estavam acostumados, são alguns dos infortúnios sofridos durante a navegação pelo rio, tanto que em determinado momento a proposta foi de chamar o rio de Marañas, palavra que significa "aflições" ou "desgraças".

O percurso foi documentado e escrito com as características da crônica, um gênero comum encontrado no início da expansão espanhola nas Américas, onde o cotidiano e as primeiras impressões do europeu são retratados e enviados como fonte de informação para a Espanha. A escrita de Carvajal é uma descrição dos fatos e das situações vivenciadas, desde o seu ponto de vista; é sensível e destaca os medos e as angústias sofridos pelos expedicionários. Dessa forma, o seu registro não só é uma fonte de informações, como ainda reflete o ponto de vista do invasor europeu. Houve fome, sede, pragas e os inevitáveis confrontos com os índios, ora amáveis ora belicosos. E foi em uma dessas batalhas que Orellana, segundo conta Carvajal, guerreou com um exército encabeçado por mulheres - tal como as guerreiras da antiga Grécia -, o que deu origem ao nome Amazonas. $\mathrm{O}$ fato é que as viagens eram sofridas e sem garantia de sobrevivência ou de riquezas e honras posteriores. O grupo expedicionário viveu uma grande aventura e, entre perdas e ganhos, após meses navegando pelo Amazonas, chegou ao Oceano Atlântico.

\section{José Toribio Medina: editor e autor da introdução histórica}

José Toribio Medina Zavala (1852-1930), importante historiador chileno, bibliógrafo, pesquisador, além de advogado, lexicógrafo, e professor na Universidad de Chile (1899), era aficionado por documentos antigos e arquivos relacionados à história. Realizou muitas viagens ao exterior - Estados Unidos, Inglaterra, França, 
Espanha, México, Argentina, entre outros -, algumas, inclusive, a trabalho, com o intuito de obter cópias de documentos importantes referentes ao Chile em bibliotecas e arquivos espanhóis. Segundo o verbete da Enciclopedia de la literatura en México (2016-2017), Fundação para as Letras Mexicanas: ${ }^{6}$

Após alguns anos de exercício da advocacia, [Toribio Medina] ingressou na carreira diplomática, atividade que lhe permitiu explorar diversos arquivos e bibliotecas da Europa e América e assim recolher uma vasta quantidade de livros, brochuras e outros documentos que acabaram por constituir a sua biblioteca (60 mil exemplares) que foi doado à Biblioteca Nacional do Chile. Por suas atividades em prol do desenvolvimento humanístico e intelectual, em 1932 a Universidade Nacional Autônoma do México lhe concedeu o título de Doutor Honoris Causa. ${ }^{7}$

O historiador publicou diversas obras, como Historia del Tribunal del Santo Oficio de la Inquisición de Lima (1887), Biblioteca Hispano-Americana, em sete volumes (publicados entre 1898 e 1907), Biblioteca Hispano-Chilena (impressa entre 1897 e 1899), em três volumes, La imprenta en La Habana (1904), Diccionario biográfico colonial de Chile (1906), La imprenta en Guatemala (1910), Chilenismos: apuntes lexicográficos (1928), entre tantos outros títulos.

Para se aquilatar a dificuldade de análise da obra de Toribio Medina basta que se avalie a sua prodigiosa capaci-

\footnotetext{
${ }^{6}$ http://www.elem.mx/autor/datos/118854. Acesso em 13 de janeiro de 2021.

${ }^{7}$ [Texto fonte] Después de algunos años de ejercer como abogado, se incorporó a la carrera diplomática, actividad que le permitió explorar diversos archivos y bibliotecas de Europa y América y con ello recolectar una vasta cantidad de libros, folletos y otros documentos que finalmente conformaron su biblioteca (60 mil ejemplares) misma que fue donada a la Biblioteca Nacional de Chile. Por sus actividades en pro del desarrollo humanístico e intelectual, en 1932 la Universidad Nacional Autónoma de México le otorga el grado de doctor Honoris Causa.
}

Cad. Trad., Florianópolis, v. 41, n $^{0}$ esp. 1, p. 213-230, jan/jul, 2021. 
dade de produção cifrada em mais de quatro centenas de trabalhos de real valor onde, se a história predomina, não são poucos os que tocam a outras ciências como a bibliografia, a numismática, as ciências naturais, a geografia, a cartografia, a etnologia, a lingüística e crítica literária, esta, aliás, a primeira manifestação de seu privilegiado espírito poligráfico. (Sampaio Garcia, 223)

A Biblioteca Americana José Toribio Medina ${ }^{8}$ reúne, em 8.431 títulos, boa parte do material recopilado pelo historiador durante suas viagens, tanto na Europa como na América, reunindo uma valiosa e abundante documentação inédita. O historiador percorreu todo o espaço geográfico colonizado pela Espanha desde o século XVI e, embora os tópicos que inclui sejam variados, seu interesse especial pela literatura imprensa e pelo Tribunal do Santo Ofício é evidente. Sampaio Garcia (1953) comenta sobre a biblioteca particular de Toribio Medina que:

Do labor incessante por mais de meio século em contacto com os meios adiantados da bibliografia de seu tempo, conseguiu Toribio Medina reunir uma preciosa biblioteca em que se encontravam exemplares raríssimos dos primórdios da colonização. Além dos 60.000 exemplares impressos, cumpra notar os 500 tornos de cópias de manuscritos, elaborados com paciência beneditina naqueles tempos em que a microfilmagem ainda não viera facilitar a tarefa dos investigadores. (Sampaio Medina, 227)

No que se refere à obra Descubrimiento del Río de las Amazonas - não só com relação a esta, mas a várias outras que escreveu,

${ }^{8}$ Fontes documentais recopiladas por José Toribio Medina, Memoria Chilena, Biblioteca Nacional de Chile. http://www.memoriachilena.gob.cl/602/w3article-673.html. Acesso em 24 de janeiro de 2021. 
de caráter histórico-geográfico ${ }^{9}$ - Medina, que tinha a vocação intelectual e a rigidez do método científico, segundo Feliu Cruz (1933), propôs estabelecer documentalmente todo o processo de origem da dominação espanhola.

Os livros não eram mais suficientes para certificar os eventos; era necessário que eles encontrassem suas provas básicas e concretas nos papéis, cartas, ofícios, relações, resumos e processos. [...] No século XIX, os quatro maiores americanistas de todos os tempos escrevem sobre isso: Martín Fernández de Navarrete, Alejandro de Humboldt, Henry Harrisse e José Toribio Medina. A eles se deve a aplicação definitiva do método científico na pesquisa documental, bibliográfica e crítica de nossa história. [...] O problemático, o inseguro, o duvidoso, nas mãos desses homens, encontraram os meios de verificação mais diretos e abriram para a ciência novos e imensos horizontes. ${ }^{10}$ (Feliu Cruz, 17-18)

Esta citação atesta o que conseguimos verificar na introdução histórica da obra de Carvajal - Relación -, escrita por Medina e dividida em onze capítulos, conforme já mencionado e detalhado anteriormente: um estudo atento e minucioso do texto, com extensa pesquisa documental e bibliográfica, que confronta os dados forne-

${ }^{9}$ Como Viajes de Diego García de Moguer al Río de la Plata, El veneciano Sebastián Caboto al Servicio de España, El descubrimiento del Océano Pacífico, Vasco Núñez de Balboa y sus compañeros e Hernando de Magallanes.

${ }^{10}$ Ya no bastaban los libros para la certificación de los sucesos; era menester que ellos [Harrisse e Medina] encontraran su prueba básica, concreta, en los papeles, cartas, oficios, relaciones, sumarios y procesos. [...] En el siglo XIX escriben los cuatro más grandes americanistas de todos los tiempos: Martín Fernández de Navarrete, Alejandro de Humboldt, Henry Harrisse y José Toribio Medina. A ellos se les debe la aplicación definitiva del método científico en la investigación documental, bibliográfica y crítica de nuestra historia. [...] Lo problemático, lo inseguro, lo dudoso, en las manos de estos hombres, encontró las vías más directas de una verificación, y abrieron a la ciencia nuevos e inmensos horizontes.

Cad. Trad., Florianópolis, v. 41, $\mathbf{n}^{0}$ esp. 1, p. 213-230, jan/jul, 2021. 
cidos em inúmeras fontes, e um historiador que se posiciona com relação à escrita do cronista, acrescentando uma série de novos dados e questionando, muitas vezes, as informações relatadas por Carvajal (algumas delas, segundo Medina, até duvidosas porque, quando confrontadas, não se sustentam). Diz ele, no início do capítulo VIII, selecionado e traduzido por nós: “[...] devemos nos limitar a contar seus principais incidentes, aclarando o que estiver dentro do nosso alcance, com relação às datas e aos lugares em que ocorreram" 11 (140).

Domingo Amunategui Solar comenta, com relação à obra Descubrimiento del Río de las Amazonas, que a memória de Medina "contém todo o interesse de um expediente de primeira mão, comentado e explicado com sábias notas, que lançam luz sobre uma região até hoje das mais desconhecidas da terra"12 (31).

\subsection{O paratexto da obra}

Com relação ao paratexto, a obra, que possui ao todo 525 páginas - das quais 239 fazem parte da introdução histórica de Medina -, informa, na segunda capa, que a tiragem é de duzentos exemplares (sendo que o exemplar consultado é o de n. 200). Após, apresenta uma dedicatória (em duas páginas) em homenagem ao Sr. Duque De T'serclaes de Tilly, ${ }^{13}$ com data de 6 de dezembro de 1894 (Sevilla), seguida da introdução histórica, composta por onze capítulos, todos escritos por José Toribio Medina. A introdução

${ }^{11}$ [...] debemos limitarnos á contarla aquí en sus principales incidencias, aclarando en cuanto esté á nuestros alcances las fechas y lugares en que se verificaron.

12 [...] encierra todo el interés de un expediente de primera mano, comentado y explicado con sabias notas, que arrojan viva luz sobre una comarca hasta hoy de las más desconocidas de la tierra.

${ }^{13}$ Pérez de Guzmán e Boza, Juan Francisco. Duque de T’Serclaes de Tilly (II). (1852-1934). Historiador, bibliófilo e político espanhol. Foi nomeado acadêmico correspondente da Real Academia de História em 1887 e acadêmico da Real Academia de Buenas Letras de Sevilha, onde ingressou em 1892 com um discurso intitulado "Antiquísimo origen de la Ciudad de Sevilla, su fundación por Hércules Tebano, y posesión de reyes que la habitaron hasta los moros". 
possui três imagens de manuscritos, redigidos e assinados, e 228 notas de rodapé explicativas. Na sequência temos a Relación, escrita por frei Gaspar de Carvajal, com dezenove capítulos e, ao final, uma lista com 27 notas explicativas e o índice.

Com relação à data de publicação da obra, nas páginas iniciais consta que é 1894 (assim como a dedicatória mencionada). No entanto, na última página, temos a seguinte informação a respeito da conclusão da impressão: "Esta obra foi impressa em Sevilha, no Escritório Enrique Rasco, rua Bustos Tavera, I. Foi concluída no dia 9 de fevereiro, MDCCCXCV [1895]."14

\section{O processo tradutório}

A tradução dos dois capítulos (VIII - A Viagem do Descobrimento e XI - Sobre os nomes do Rio), da introdução histórica de José Toribio Medina, em Descubrimiento del Río de las Amazonas (1894), adquiriu para nós uma dimensão maior do que a esperada, ao iniciar a tarefa, que além de ter um viés de documento histórico, também é uma narrativa que permite a análise da diversidade sociocultural dos povos originários.

Os textos de Medina não ocultam em nada a saga dos espanhóis em consolidar a conquista, encontrar tesouros de ouro e prata, assim como expandir o reino peninsular em terras americanas, mas, também, são honestos ao mostrar como a cobiça, imbuída de um ideal de conquista, quase leva os expedicionários à ruína e à perda das próprias vidas. Eles compreendem elementos culturais que, ao serem traduzidos por nós, estão inseridos em um contexto pluricultural, porque nos mostram os procedimentos do colonizador, da posse da terra - comentando os costumes e o contato com os povos indígenas desde uma perspectiva eurocentrista - e da imposição de sua própria cultura aos indígenas. Burke (117) comenta

${ }^{14}$ Imprimióse esta obra en Sevilla, en la Oficina de Enrique Rasco, calle Bustos Tavera, I. Acabóse á IX días de Febrero de MDCCCXCV.

Cad. Trad., Florianópolis, v. 41, $\mathbf{n}^{0}$ esp. 1, p. 213-230, jan/jul, 2021. 
que "quando um texto é traduzido, ele é extraído da cultura que o criou e posto em um lugar novo." Ou seja, traduzir as narrativas do Novo Mundo, enviadas à Europa, foi para nós um desafio ético e lexical, já que tivemos que levar em consideração, principalmente, a compreensão das diferenças temporais e socioculturais dos aspectos linguísticos.

Por isso, houve a necessidade de realizar um planejamento prévio e que também se deu no momento da tradução, com pesquisa em livros, artigos e sites especializados. Um deles foi a procura de documentos históricos, como os encontrados no Portal de Archivos Españoles - PARES, ${ }^{15}$ que atestam a presença do capitão Orellana e a defesa dos interesses da coroa espanhola na expansão das colônias do continente americano. Outras fontes importantes também foram consultadas, como o banco de dados CORDE (Corpus Diacrónico del Español), ${ }^{16}$ o Nuevo Tesoro Lexicográfico de la lengua Española ${ }^{17}$ que reúne uma ampla seleção de dicionários ao longo dos últimos quinhentos anos, assim como o Dicionário Etno-Histórico da Amazônia Colonial (2007), de Antonio Porro, com relação aos nomes de povos e territórios, aldeias e lugares, entre outros. Os resultados de toda a pesquisa forneceram subsídios importantes para evitar a manipulação do texto, no sentido de omitir, acrescentar, abrandar ou mesmo exaltar algumas situações e, igualmente, para evitar enganos temporais quanto aos significados implicados nos vocabulários usados.

Quanto às 228 notas de rodapé, já mencionadas, cabe dizer que no capítulo VIII há nove notas, a maioria delas de caráter explicativo, que confrontam dados da Relación, de Carvajal, com os trechos publicados na obra de Oviedo e em outros documentos. Acrescentamos três notas de tradução [N.T], explicativas, para vocábulos que decidimos manter e que apresentam basicamente a

15 Gobierno de España. Ministerio de Cultura y Deporte. http://pares.mcu.es/ ParesBusquedas20/catalogo/description/315440?nm.

${ }^{16}$ https://www.rae.es/banco-de-datos/corde.

${ }^{17} \mathrm{http} / / /$ ntlle.rae.es/ntlle/SrvltGUILoginNtlle.

Cad. Trad., Florianópolis, v. 41, $\mathbf{n}^{0}$ esp. 1, p. 213-230, jan/jul, 2021. 
mesma grafia no português: uma para falar do tipo de embarcação, bergantín/bergantim, outra sobre o ofício de "piloto" nas embarcações, e a última sobre a abreviatura "P." de Provincial. Quanto ao capítulo XI, há vinte e três notas do autor e nenhuma de tradução.

Mencionamos, na sequência, algumas decisões mais gerais em relação a algumas escolhas na tradução, para depois entrar em outras questões mais particulares. No caso das datas e meses, que abundam no texto fonte, decidimos por manter como estavam: em números romanos (para as datas) quando assim se apresentavam, e com a $1^{\mathrm{a}}$ letra em maiúscula para os meses do ano. O substantivo río/Río, seguido do nome do mesmo, que ora aparece em minúscula ora em maiúscula, também mantivemos tal qual estava. Para pueblo e poblado, este com o sentido do primeiro, decidimos por "aldeia" Para provincia/província, mantivemos o termo, baseadas no que explana Antonio Porro (2007):

As fontes mais antigas (ca. 1540-1640) referem-se amiúde a províncias e senhorios amazônicos, termos de matriz românico-medieval que haviam se justificado no mundo andino, de onde, aliás, procediam as primeiras explorações amazônicas. Sem entrar no mérito da questão, ainda objeto de debate entre os especialistas, de uma provável maior complexidade sócio-política na Amazônia que os primeiros exploradores encontraram, bastará lembrar, aqui, que no decorrer do século XVII aqueles termos foram abandonados pelos cronistas luso-brasileiros em favor das categorias menos pretensiosas de nações e gentios (Porro 1993; 1996). Uma vez que o referido silêncio das fontes sobre o assunto não permite, no atual estágio dos conhecimentos, esclarecer se a grande maioria dos etnônimos registrados neste Dicionário se refere a tribos, sub-tribos, sipes ou mesmo grupos locais, optou-se por evitar tais qualificativos, salvo quando o termo tribo é abonado pela literatura etnográfica mais recente (Porro, 8). 
Para os topônimos brasileiros, alguns nomes de rio como Madeira, Tapajós, Solimões, Paranaiba (nome indígena do rio Xingu) e Amazonas, e nomes de localidades como a ilha do Marajó, aparecem escritos exatamente assim, no texto fonte, mas sem os acentos gráficos. Optamos por acentuá-los. No caso de lugares e rios estrangeiros, como Cubagua (ilha venezuelana) e Curaray (rio do Equador e do Peru, e afluente do rio Napo), a grafia foi mantida. No caso de territórios e províncias - como Aparia, Machiparo e Omagua - mantivemos a grafia. Segundo o Dicionário Etno-Histórico da Amazônia Colonial, Aparia é "um dos nomes com que as fontes quinhentistas se referem àquele que, no século 17, seria conhecido como o território dos Omagua do alto Amazonas" (Porro, 18); Machiparo "era uma província que ocupava a marg. dir. do Solimões, desde acima do Tefé até o Coari, identificável com os Curucirari ou Aisuari do séc. 17" (Porro, 60); e Omagua "é a grande província de Aparia ou Carari do Amazonas peruano e do alto Solimões, que já impressionara os viajantes do séc. 16 pela boa disposição, denso povoamento e aparente civilidade de suas grandes aldeias, [...] (Porro, 76).

No caso do rio Marañón, a princípio, simplesmente o aportuguesamos - Maranhão. Porém, no decorrer dos textos, principalmente no capítulo XI (escrito por Toribio Medina), que trata dos vários nomes do rio - que nem eles sabiam ao certo qual era e de onde procedia esse nome - percebemos o equívoco:

Se fosse dito que o nome de Marañón ou Maranhão procedia de algum navegador português, não poderíamos, da nossa parte, contradizer tal afirmação; mas visto que quem dá a notícia assevera que o nome provém de origem espanhola, é o caso de negar essa suposição ${ }^{18}$ (Carvajal, 236).

\footnotetext{
${ }^{18}$ Si se dijese que el nombre de Marañón ó Maranhao procedía de algún navegante portugués, no podríamos por nuestra parte contradecir semejante aserción; pero como los que dan la noticia aseveran que el nombre procede de origen español, estamos en el caso de negar aquella suposición.
} 
Outra constatação foi percebida, no capítulo VIII, sobre a abreviatura P. que antecede o nome de Gaspar de Carvajal, que não se referia à Padre - como a princípio pensamos - e sim à Provincial, "o religioso que tem governo e superioridade sobre todas as casas e conventos de uma província" ${ }^{19}$ (Academia Autoridades, 416, $1^{20}$ ), ou seja, um cargo eclesiástico de governo na igreja Católica. A comprovação se deu através da leitura do capítulo II da introdução de Toribio Medina, que trata de Carvajal: "na verdade foi o fundador da Ordem de Santo Domingo no Peru e o primeiro vigário provincial que ali teve, até agora" 21 (Carvajal, 19). Em função disso, mantivemos a abreviatura - já que temos o mesmo correspondente no português - e acrescentamos uma nota de rodapé explicativa. Essa mesma abreviatura também foi encontrada no final do capítulo XI, em "P. Manuel Rodríguez".

A tradução de textos, como vimos, implica em escolhas cuidadosas, principalmente com relação ao léxico. É necessário lembrar que existe toda uma perspectiva histórica envolvida (século XVI) e que a tradução é dirigida a uma sociedade multicultural do século XXI, onde boa parte dela é consciente no que diz respeito ao preconceito. Por isso citamos, como exemplo, a palavra "índio", que é encontrada nos textos tanto em situações de confronto como em situações amigáveis com os expedicionários. A palavra foi mantida, na tradução, em detrimento de "indígena", que seria a melhor escolha lexical para ratificar o pertencimento e a identidade do autóctone no continente americano. Indígena, como termo dicionarizado no Priberam é originado no latim, e adverte que se trata do que é natural do local, "que já estava antes". ${ }^{22}$ Manter

${ }^{19}$ El religioso que tiene el gobierno y superioridad sobre todas las Casa y Conventos de una Provincia.

${ }^{20}$ Nuevo Tesoro Lexicográfico de la lengua Española. http://ntlle.rae.es/ntlle/Srv ltGUIMenuNtlle?cmd $=$ Lema\&sec =1.0.0.0.0. Acesso em 28 de janeiro de 2021.

${ }^{21}$ en efecto fué el fundador de la Orden de Santo Domingo en el Perú, y el primer vicario provincial que allí tuvo, hecho hasta ahora.

22 https://dicionario.priberam.org/ind\%C3\%ADgena. Acesso em 12 de janeiro de 2021 .

Cad. Trad., Florianópolis, v. 41, no esp. 1, p. 213-230, jan/jul, 2021. 
a palavra "índio" foi uma decisão de tradução para preservar o vocábulo usado naquele contexto de narrativa e permitir ao leitor hodierno o estranhamento comumente causado ao ler um texto de 1541, quando apenas era utilizada a palavra "índio". A entrevista concedida por Daniel Munduruku, ${ }^{23}$ mostra essa palavra associada a uma imagem pré-concebida de preguiça e ignorância em relação ao autóctone, ainda perpetuada no imaginário popular de muitos. Assim, por a língua estar sempre em movimento, é importante que o leitor perceba que mesmo mantendo seu uso, na atualidade, o significado semântico apresenta diferenças.

Para finalizar, deixamos aqui algumas linhas sobre nós, as tradutoras, e sobre as contribuições dos textos traduzidos. Com relação a nós, destacamos que a tradução se apoiou - além da pesquisa documental, histórica e lexical, já mencionadas - no conhecimento da língua espanhola e da cultura dos Séculos de Ouro espanhol por parte das tradutoras, provenientes das próprias teses desenvolvidas $^{24}$ e dos estudos e pesquisas realizados no Núcleo Quevedo de Estudos Literários e Traduções do Século de Ouro, ${ }^{25}$ um local de colaboração e diálogo entre vários pesquisadores/tradutores. No que diz respeito às traduções, ressaltamos que as contribuições dos textos são significativas, não só porque resgatam fatos históricos apresentados por Toribio Medina, a partir dos escritos de Carvajal, que longe de qualquer idealismo, momentos sombrios ou vagueza, escreveu para informar reis e leitores atemporais, como também

${ }^{23}$ Daniel Munduruku: Eu não sou índio, não existem índios no Brasil. Nonada. Jornalismo Cultural. 21/11/2017. Porto Alegre. http://www.nonada.com. br/2017/11/daniel-munduruku-eu-nao-sou-indio-nao-existem-indios-no-brasil/.

${ }^{24}$ Cesco, Andréa. Sueños y discursos, de Quevedo: barroco, sátira e tradução. Florianópolis, 2007 (PPGLit/UFSC/CAPES). http://www.tede.ufsc.br/teses/ PLIT0286-T.pdf. Bezerra, Mara Gonzalez. Tradução comentada da peça teatral Amor es más laberinto de Sor Juana Inés de La Cruz: o emaranhado jogo das antíteses. 2016 (PGET/UFSC/CAPES). http://www.bu.ufsc.br/teses/PGET0316-T.pdf.

${ }^{25}$ Ver pesquisas em andamento e publicações. O Núcleo Quevedo está ligado ao Programa de Pós-Graduação em Estudos da Tradução. Universidade Federal de Santa Catarina. https://nucleoquevedo.paginas.ufsc.br/.

Cad. Trad., Florianópolis, v. 41, n $^{0}$ esp. 1, p. 213-230, jan/jul, 2021. 
evidenciam e trazem ao conhecimento a presença espanhola na formação da identidade social e cultural dos habitantes da região amazônica, no século XVI. Ademais, elas também fornecem subsídios para os estudos pós-coloniais porque o leitor poderá conhecer um pouco mais da história e ter elementos étnicos para refletir sobre a sua identidade e cultura, adquirindo uma formação crítica que valoriza saberes heterogêneos.

\section{Referências}

Amunategui Solar, Domingo. José Toribio Medina. Santiago de Chile (Chile): Prensas de la Universidad de Chile, 1932. Disponível em Biblioteca del Congreso Nacional de Chile. Estantería Digital: https://obtienearchivo.bcn.cl/obtienearchiv o? id = documentos $/ 10221.1 / 54585 / 2 / 53964$. pdf\&origen $=$ BDigital .

Burke, Peter; Po-Chia Hsia, Ronnie (Orgs.). A tradução cultural nos primórdios da Europa Moderna. Tradução de Roger Maioli dos Santos. São Paulo: Editora Unesp, 2009.

Carvajal, Gaspar de; Medina, José Toribio. Descubrimiento del Río de las Amazonas. Introdução histórica e ilustrações de José Toribio Medina. Sevilla: Imprenta de E. Rasco, 1894. https://www2.senado.leg.br/bdsf/item/id/518714.

Carvajal, Gaspar de; Rojas, Alonso de; Acuña, Cristóbal de. Descobrimentos do Rio das Amazonas. Série 2a, Vol. 203, Brasiliana - Biblioteca Pedagógica Brasileira. Traduzido e anotado por C. de Melo-Leitão. São Paulo, Rio de Janeiro, Recife, Porto Alegre. Companhia Editora Nacional, 1941.

Feliu Cruz, Guillermo. Medina y la Historiografía Americana. Un ensayo sobre la aplicación del método. Santiago de Chile (Chile): Imprenta Universitaria, Estado 63, 1933. 52p. Disponível em Biblioteca del Congreso Nacional de Chile. Estantería Digital: https://obtienearchivo.bcn.cl/obtienearchivo?id=document 
os $/ 10221.1 / 54580 / 2 / 33633$.pdf\&origen $=$ BDigital .

Porro, Antonio. Dicionário Etno-Histórico da Amazônia Colonial. Cadernos do IEB (Instituto de Estudos Brasileiros). São Paulo: IEB/USP, Gráfica Imprensa da Fé, 2007. http://www.ieb.usp.br/dicionario-etno-historico-da-amazoniacolonial/.

Sampaio Garcia, Rozendo. "José Toribio Medina, o historiador da América", Revista de História. v. 6, nº 13, 1953. https://doi.org/10.11606/issn.2316-9141. v6i13p223-229.

Andréa Cesco. E-mail: andrea.cesco@gmail.com. https:orcid.org/0000-00024708-186X.

Mara Gonzalez Bezerra. E-mail: mara.gonzalez.letras@gmail.com. https://orcid. org/0000-0001-8390-5910.

Cad. Trad., Florianópolis, v. 41, $\mathbf{n}^{0}$ esp. 1, p. 213-230, jan/jul, 2021. 230 